\title{
A WELCOME FROM THE EDITOR
}

\section{David Westgarth, Editor, BDJ Student}

Hello and welcome to the Autumn 2021 issue of BDJ Student.

It's been a strange old year, and the concerns raised in January are still as relevant now as they were then. As we enter into the 'freedom' stage of the pandemic in the UK, with each nation taking its own steps to allow normalities to return, attention now turns to the finer details - PPE, social distancing, fallow times - to ensure dentistry keeps pace with the rest of society's changes.

\section{'Dentistry forced through years of change in a matter of weeks to survive, and students were no different, yet in some ways they were better prepared than most for this.'}

What is obvious is how much of a moveable feast these things have been since March 2020. Dental students have been hugely impacted. Some concerns have been raised about the lack of readiness some feel, and we are beavering away to alleviate these concerns and give you every chance you need to be the best version of you.

Perhaps the biggest change we've seen is the pace of change relating to digital and online learning. Dentistry forced through years of change in a matter of weeks to survive, and students were no different, yet in some ways they were better prepared than
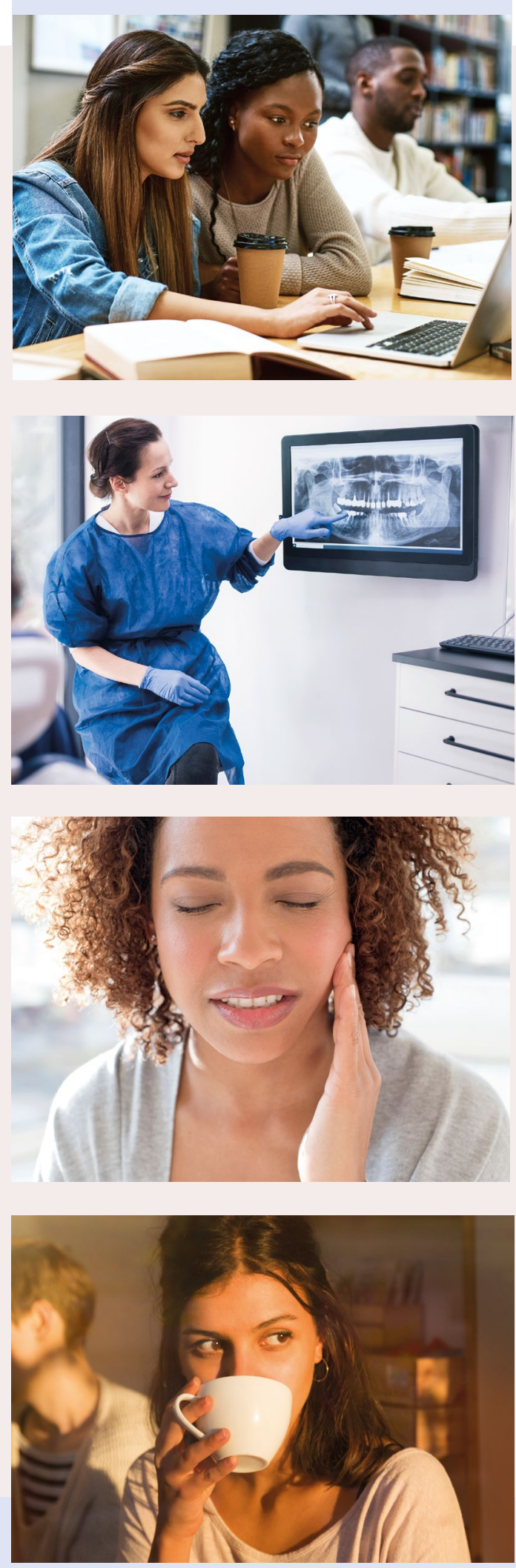

most for this. After all, you've grown up with technology, you know better than anyone how to make the most of it, and you will be the at the forefront of evolution when it comes to digital advances.

To keep up with the pace of advancements, and to continue bringing you thought-provoking, insightful and timely content, $B D J$ Student is not immune from change. That's why from September, BDJ Student is moving to an online only platform, publishing content regularly throughout the year. I know many of you value seeing your name in print, and this change will enable us to publish more content more often. It will also mean many of the excellent articles I have rejected in the past due to the print cycles will now be in pole position to be considered. We'll bring you the same high-quality professional insight, careers advice and clinical tips as we have done - it will now be at the behest of your fingertips and accessible whenever and wherever you are - there will simply be more of it!

That's not the only change. It's my absolute pleasure to announce that Nicka Kafil is the new BDJ Student student editor, replacing outgoing incumbent Sophia Antoniou. I can't wait for Nicka to take up the role and as the world opens up, you can look forward to more high-quality musings from Nicka throughout the portfolio.

For those starting on their journey or for those starting the final year of their student journey, from everyone here at the BDA and from BDJ Student, we wish you the very best of luck.

https://doi.org/10.1038/s41406-021-0249-8 